\title{
Aptamer-gated Ion Channel for Ultrasensitive Mucin 1 Detection
}

Mengying Pan\#, Jiarong Cai\#, Si Li, Liguang Xu, Wei Ma*, Chuanlai Xu, Hua Kuang* International Joint Research Laboratory for Biointerface and Biodetection, State Key Lab of Food Science and Technology, School of Food Science and Technology, Jiangnan University, Wuxi, Jiangsu, 214122, PRC.

\#The two authors contributed equally to this paper.

*Corresponding Authors: mawei209@126.com; kuangh@jiangnan.edu.cn;

\section{Table of Contents:}

\section{Supplementary experimental methods}

1.1 Materials and reagents

1.2 Fabrication of the Au-AAO ion channel

1.3 Apparatus and characterization

1.4 Electrochemical measurements

\section{Supplementary Figures and Tables}

2.1 Structural Characterization of Au-AAO Ion Channel

2.2 Ion transport behavior of $\mathrm{Au}-\mathrm{AAO}$ ion channels

2.3 MUC1 detection based on Au-AAO ion channels

\section{Supplementary References}




\section{Supplementary experimental methods}

\section{Synthesis of Au NPs ${ }^{1,2}$}

The trisodium citrate reduction method was used to synthesize uniform $35 \mathrm{~nm} \mathrm{Au}$ NPs. The synthesis process was as follows: $5 \mathrm{~mL}$ of $4 \mathrm{~g} / \mathrm{L} \mathrm{HAuCl}_{4}$ was added to 195 $\mathrm{mL}$ of ultrapure water, stirred and then heated at $350^{\circ} \mathrm{C}$. After boiling, $1.5 \mathrm{~mL}$ of seed solution $(8 \mathrm{~nm})$ and $0.8 \mathrm{~mL}$ of $1 \%$ trisodium citrate solution were added and thoroughly mixed. Heating and stirring were continued until the color of the solution turned red then heating was discontinued. The solution was stirred at low speed until it reached room temperature.

The seed solution $(8 \mathrm{~nm})$ included trisodium citrate and sodium borohydride as reducing agents. $1.47 \mathrm{mg}$ of trisodium citrate was dissolved in $20 \mathrm{~mL}$ of ultrapure water. $0.5 \mathrm{~mL}$ of $4 \mathrm{~g} / \mathrm{L} \mathrm{HAuCl}_{4}$ solution and $0.6 \mathrm{~mL} 0.1 \mathrm{M}$ sodium borohydride solution were added with rapid stirring until the color of the mixed solution changed to orange and was stable.

\section{Analysis of Au NPs particle size}

Dynamic light scattering using a nanoparticle size analyzer from Zetasizer Nano ZS system (Malvern) with a $632.8 \mathrm{~nm}$ laser was used to measure Au NPs particle size. Different aperture size and channel densities could result in different rectified performance as gold nanofilms are composed of three sizes of Au NPs. To determine the best rectification effect, a particle size of $35 \mathrm{~nm}$ was selected.

\section{Zeta potential measurement}


A Zetasizer Nano ZS system (Malvern) with a $632.8 \mathrm{~nm}$ laser was used to measure zeta potential. Zeta potential is capable of indirectly reflecting the charge type and the amount of surface charge of a particle. In view of the difficulty in measuring the zeta potential of the Au-AAO ion channel, instead, we measured the zeta potential of the five systems in solution phase: the unmodified Au NPs, the aptamer-modified Au NPs, the MUC1, the unmodified Au NPs added MUC1 (Incubated for $12 \mathrm{~h}$ ), and the aptamermodified Au NPs added MUC1 (12 h). MUC1 hybridized with the aptamer which was immobilized on the surface of the Au NPs. The molecular weight of MUC1 is $14 \mathrm{kDa}$.

\section{Apparatus and characterization}

The JEOL JEM-2100 transmission election microscope operating at an acceleration voltage of $200 \mathrm{kV}$ was used to acquire TEM images. SEM images were obtained using a Hitachi S-4700 scanning electron microscope. Measurement of UVVis spectra was obtained using a UNICO 2100PC UV-Vis spectrophotometer. The sizes of the nanoparticles were measured with a Zetasizer Nano ZS system (Malvern) with a $632.8 \mathrm{~nm}$ laser. A Shanghai CHI-760 electrochemical workstation was used for the electrochemical tests. 


\section{Supplementary Figures and Tables}

2.1 Structural Characterization of Au-AAO Ion Channel

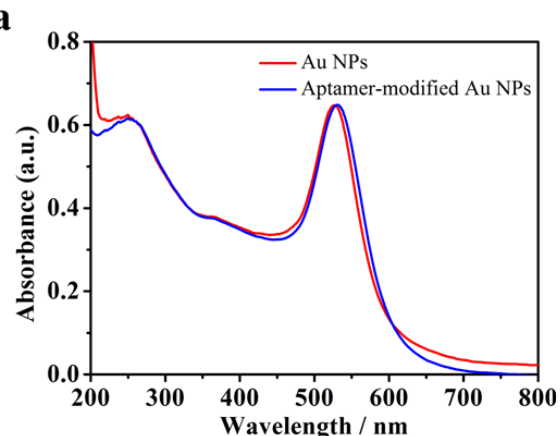

b

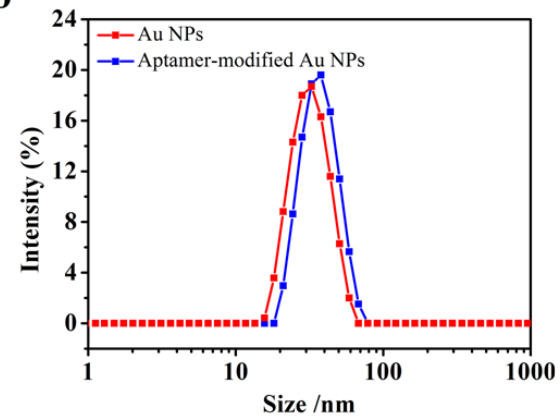

Figure S1. (a) The UV-Vis spectra before and after Au NPs modified MUC1 aptamer.

(b) Particle size distributions before and after Au NPs modified MUC1 aptamer.

a
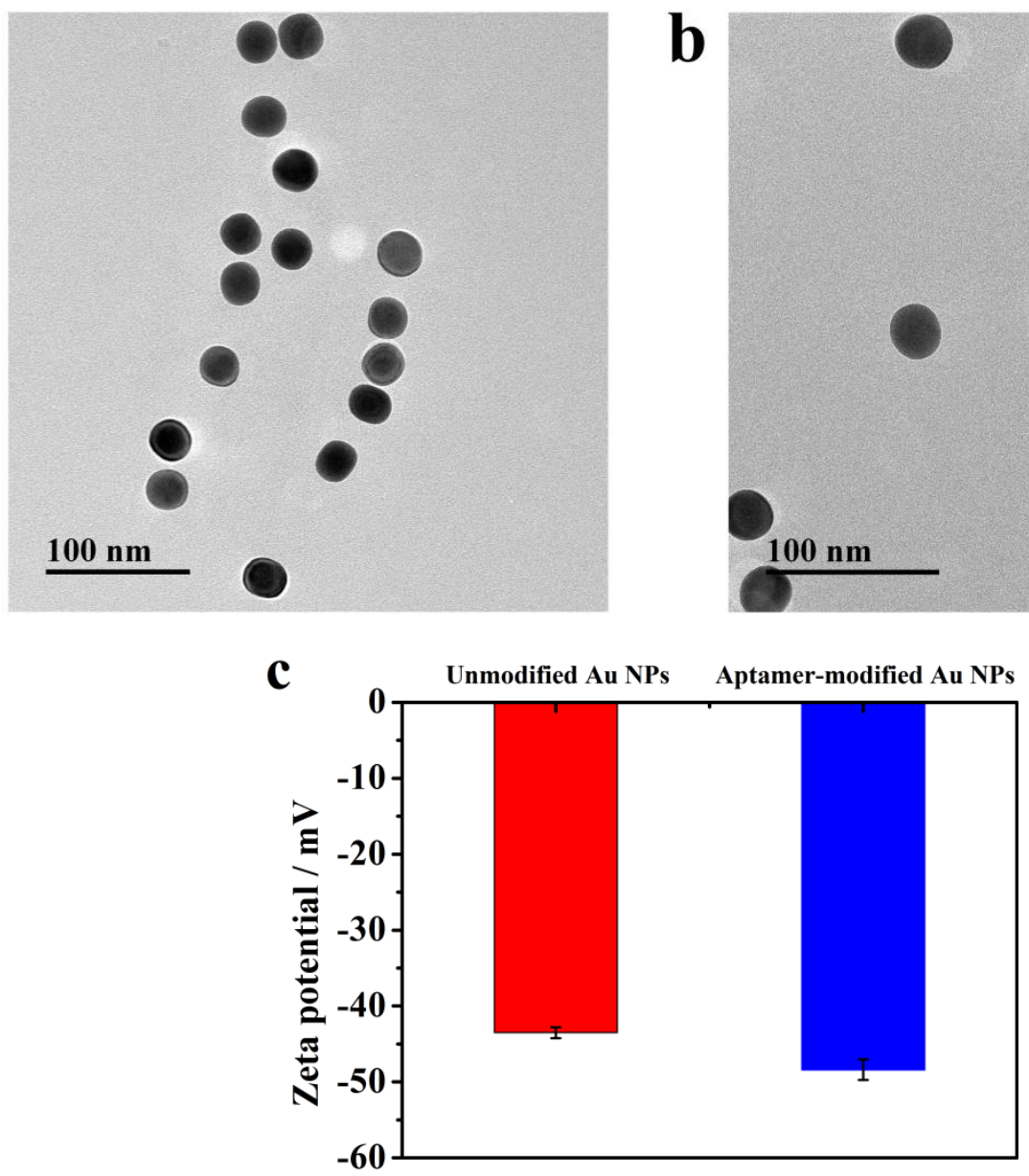

b

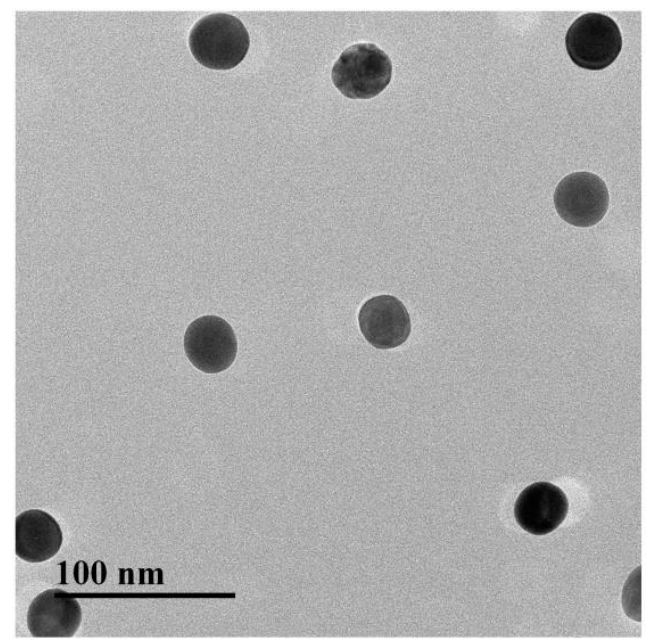



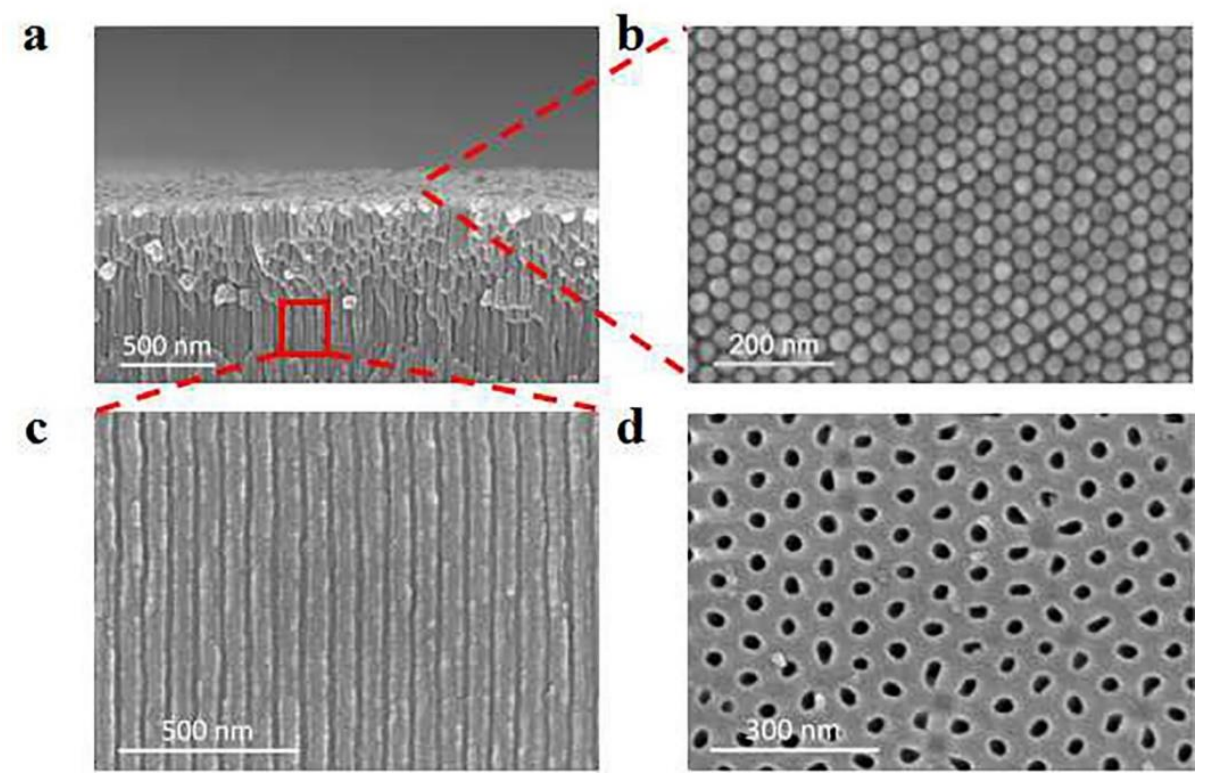

Figure S3. Structural characterization of the Au-AAO ion channel. (a) SEM image of the cross section of Au-AAO ion channel. (b) SEM image of monolayer gold nanofilm. (c and d) SEM image of cross section and surface of AAO.

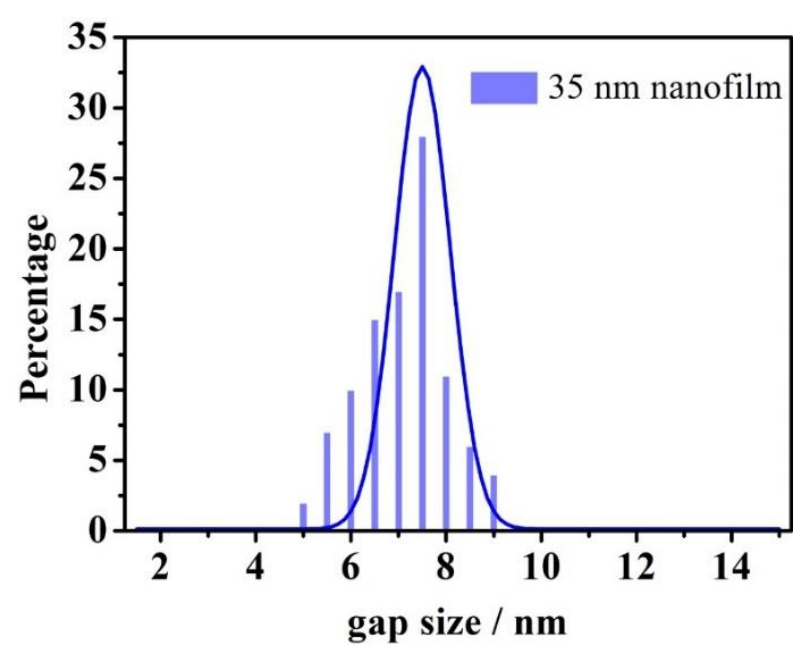

Figure S4. Statistics of gap size between adjacent NPs of gold nanofilms. 


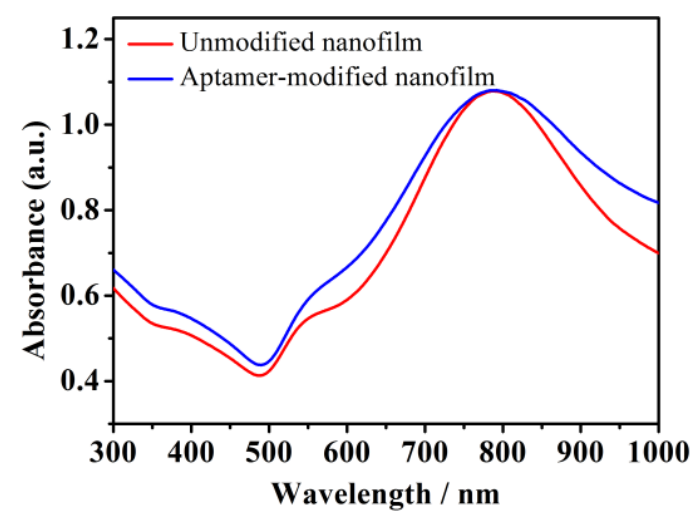

Figure S5. The UV-Vis spectra of the unmodified and aptamer-modified gold nanofilm.

\section{a}

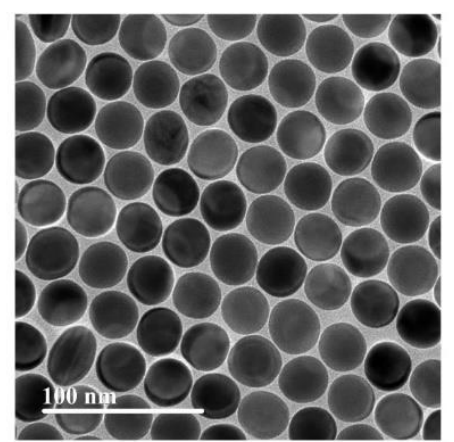

b

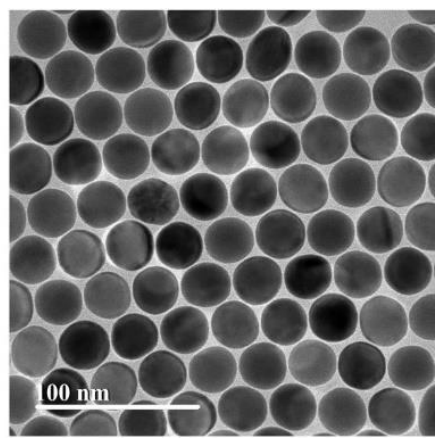

Figure S6. TEM images of (a) the unmodified gold nanofilm and (b) the irrelevant DNA-modified gold nanofilm. 
2.2 Ion transport behavior of Au-AAO ion channels

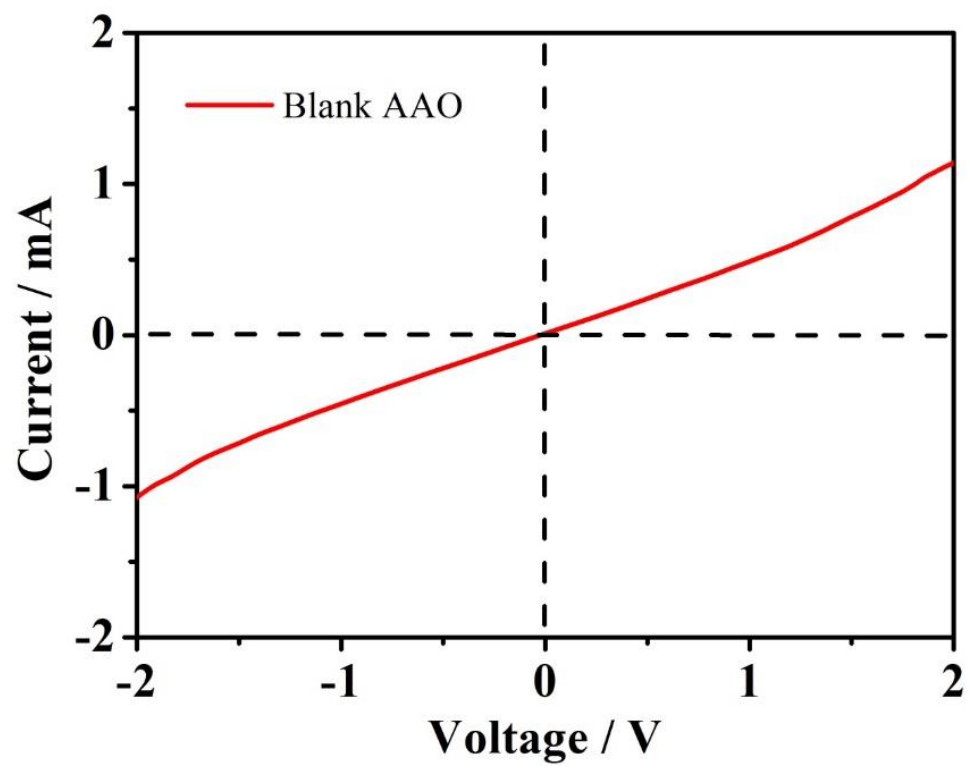

Figure S7. The I-U curves of single AAO.
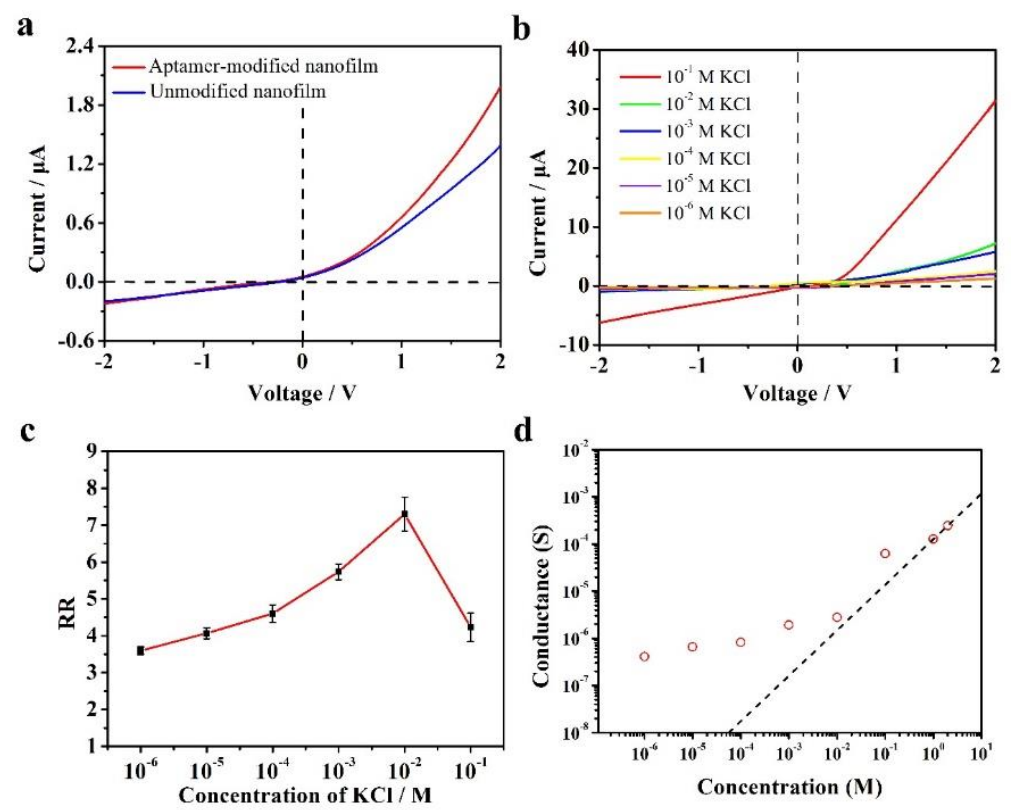

Figure S8. Ion transport behavior of the Au-AAO ion channel. (a) Comparison of I-U curves before and after gold nanofilm modified with MUC1 aptamer. (b) The I-U curves of Au-AAO ion channels at different electrolyte $(\mathrm{KCl})$ concentrations. (c) Comparison of RR of Au-AAO ion channels at different $\mathrm{KCl}$ concentrations. (d) The transmembrane ion conductance (circles) was clearly far from the bulk value (dashed line) in the low-concentration electrolyte, indicating that ion transport is completely controlled by the surface charge. 


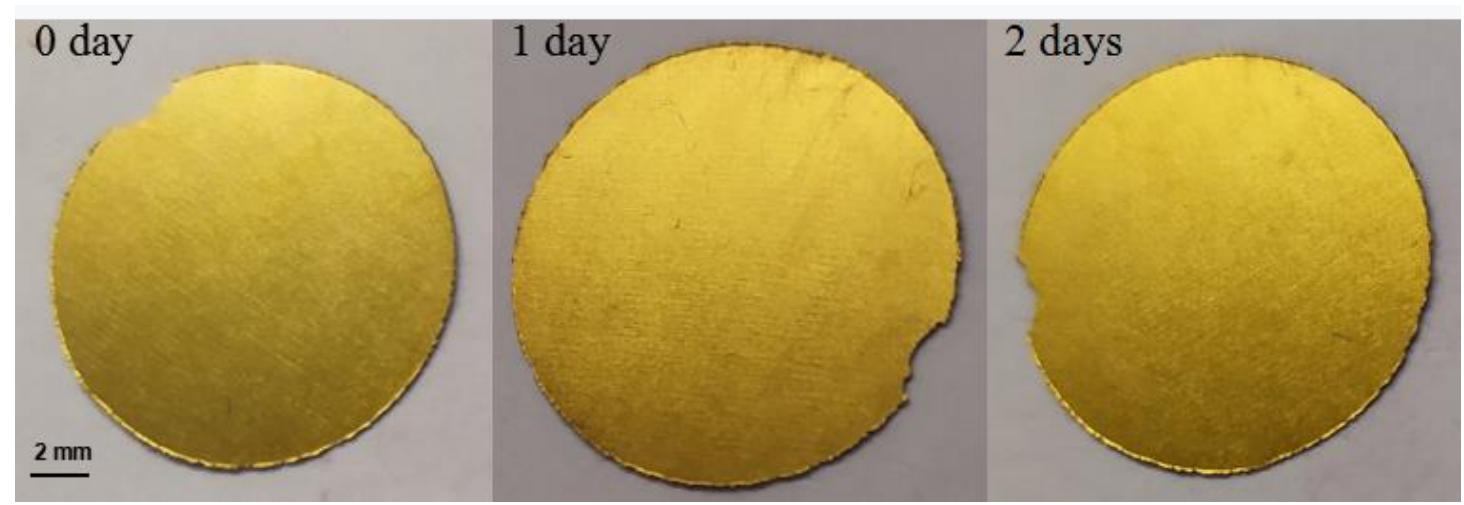

Figure S9. Photos of heterogeneous membranes immersed in electrolyte solution for different times.

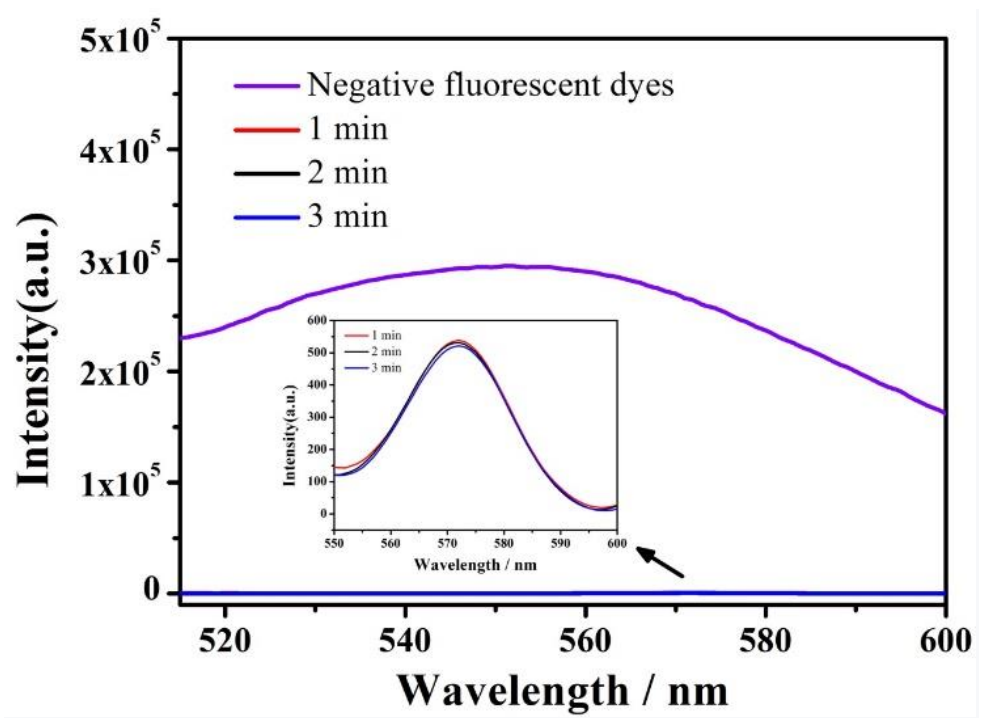

Figure S10. Permeability of negatively charged fluorescent dyes (carboxy fluorescein) on Au-AAO ion channel system. 


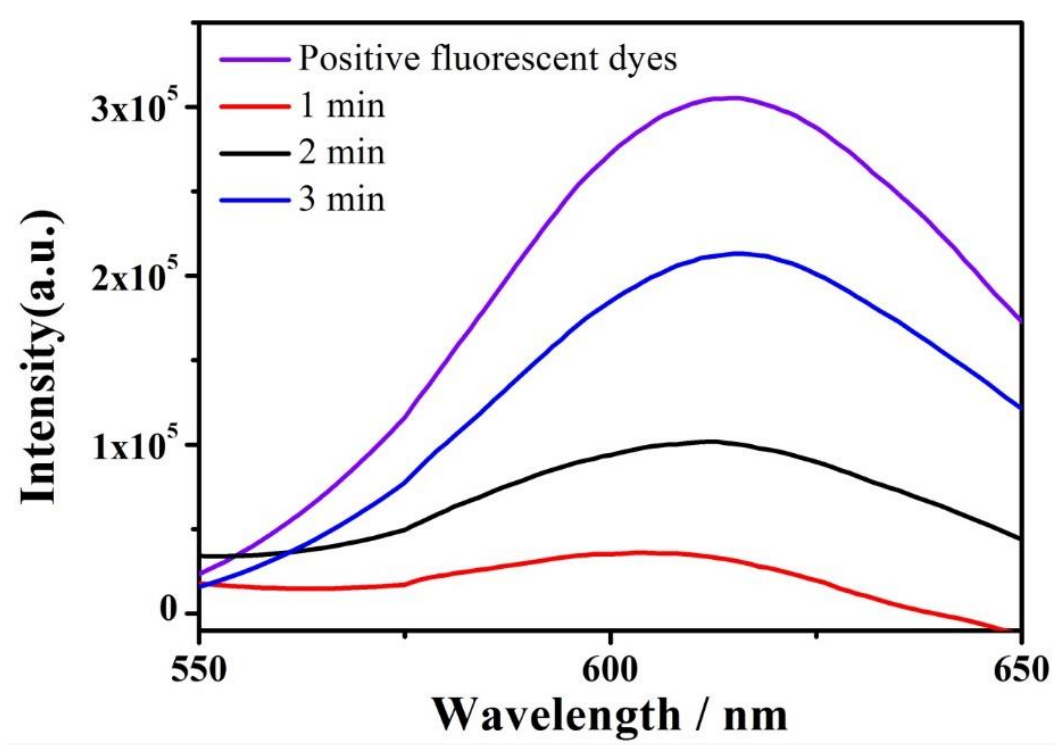

Figure S11. Permeability of positively charged fluorescent dyes (disodium iodide) on $\mathrm{Au}-\mathrm{AAO}$ ion channel system.

2.3 MUC1 detection based on Au-AAO ion channels

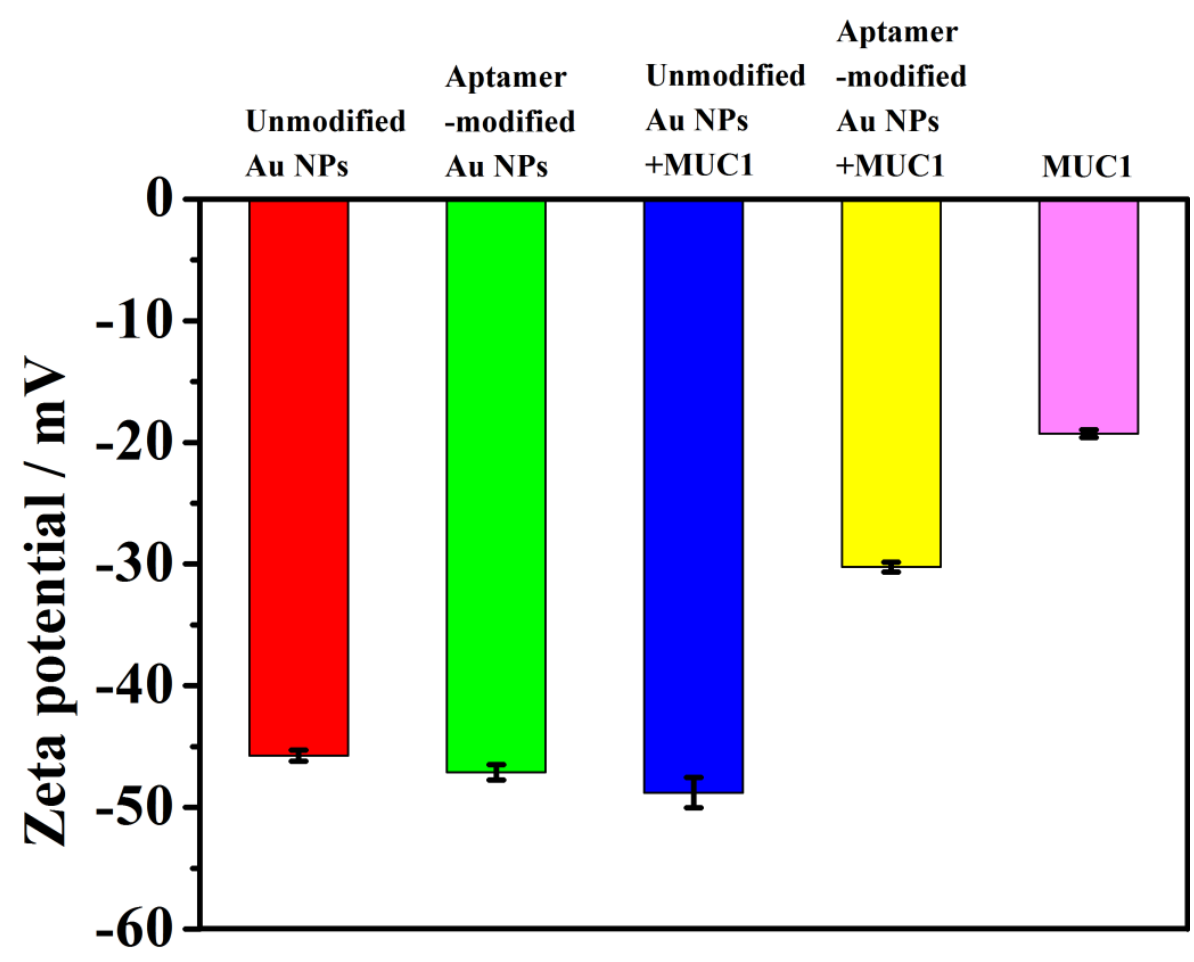

Figure S12. The Zeta potential of the five systems in solution phase. 


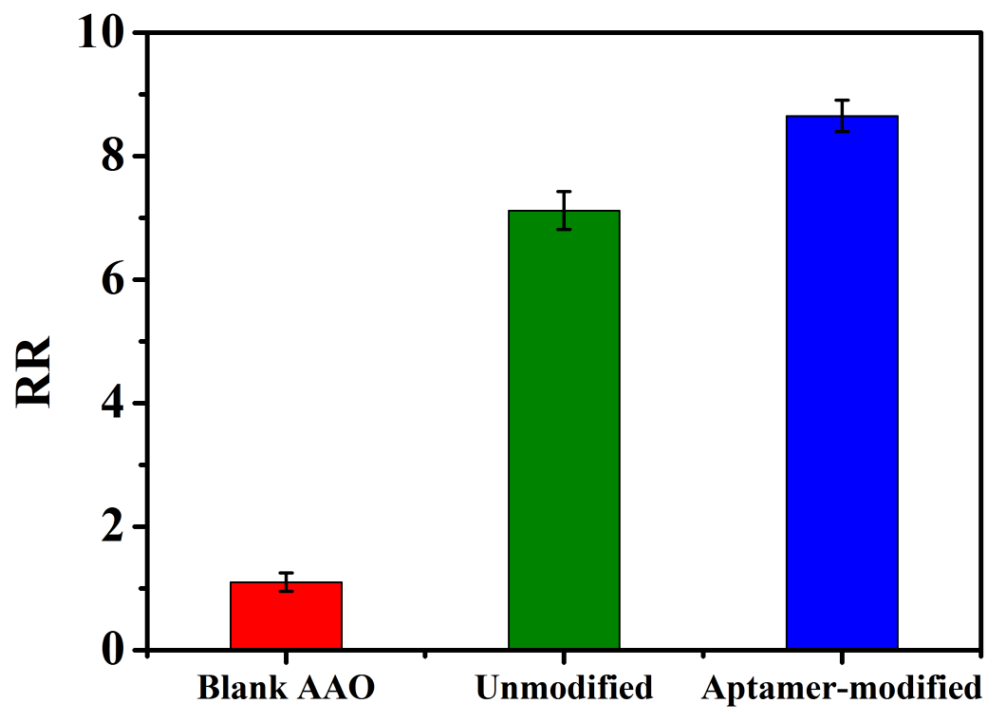

Figure S13. Rectification ratio (RR) statistics of the blank AAO, the unmodified gold nanofilm and the aptamer-modified gold nanofilm.

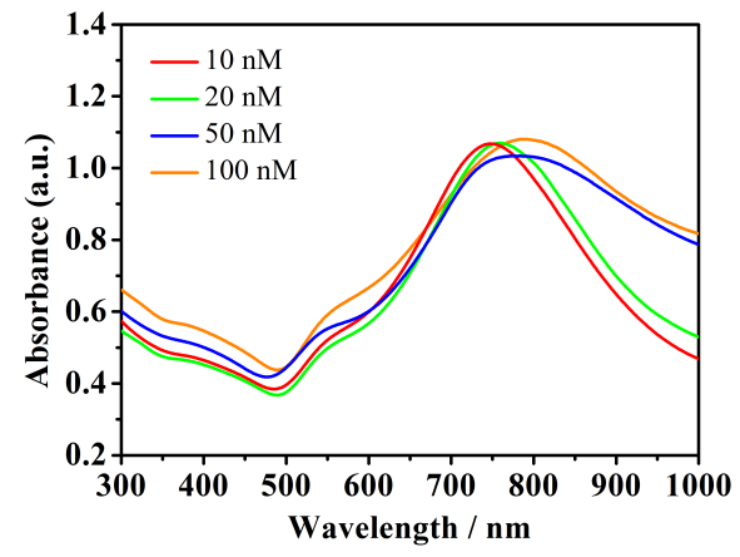

Figure S14. The UV-Vis spectra of gold nanofilm modified with different aptamer concentrations (10 nM, $20 \mathrm{nM}, 50 \mathrm{nM}, 100 \mathrm{nM})$. 

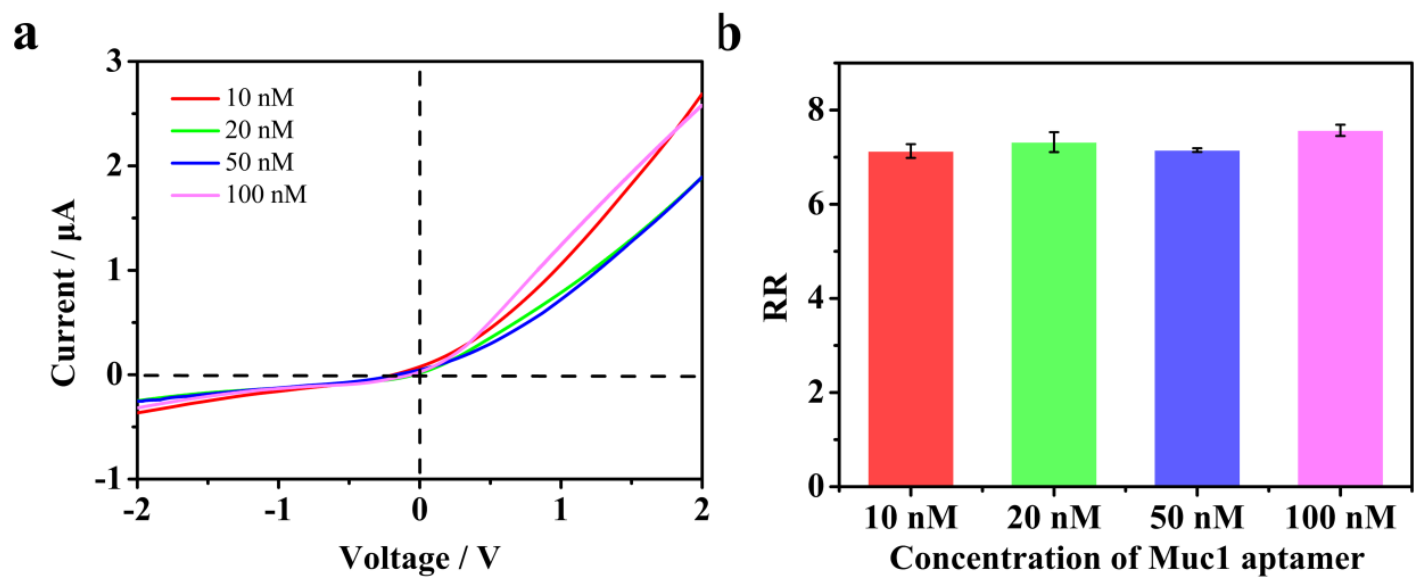

Figure S15. (a) The I-U curves of Au-AAO ion channels modified with different aptamer concentrations. (b) Comparison of RR of Au-AAO ion channels modified with different concentrations of MUC1 aptamers.

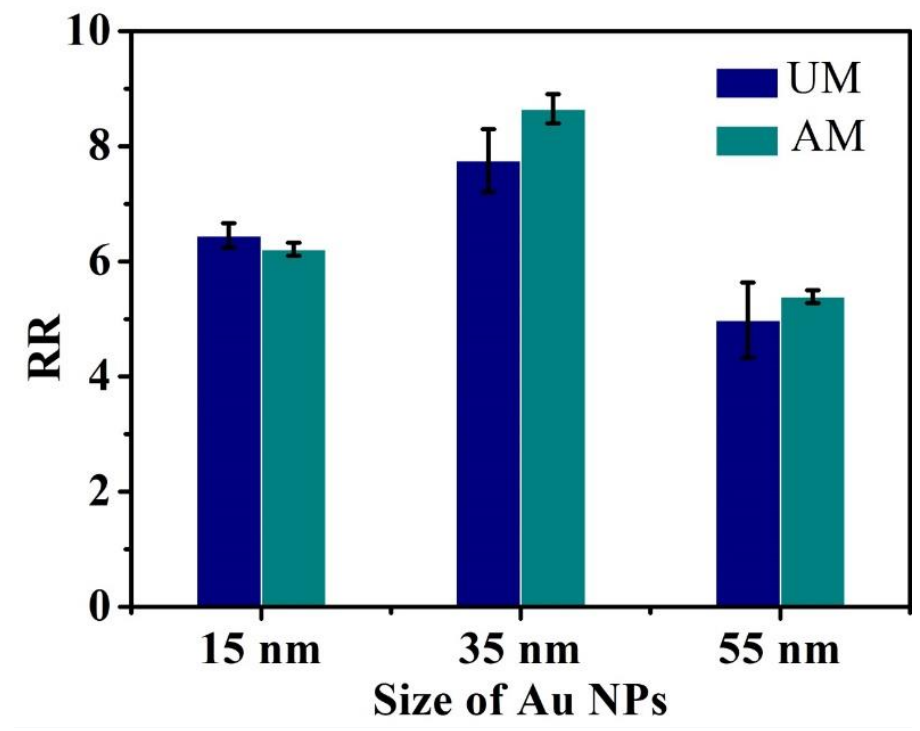

Figure S16. RR performance of the Monolayer UM and AM system composed of different sizes Au NPs. 


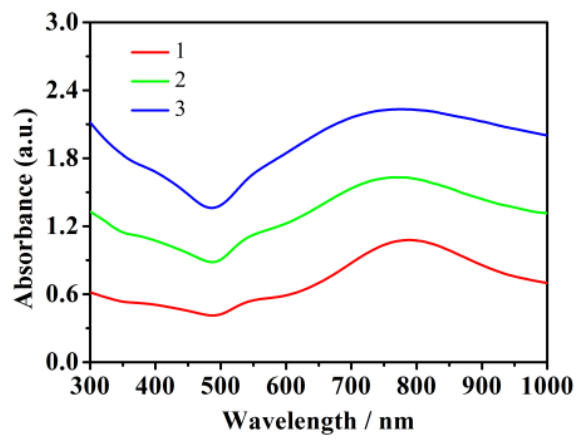

Figure S17. The UV-Vis spectra of 1-3 layers of the unmodified gold nanofilm.

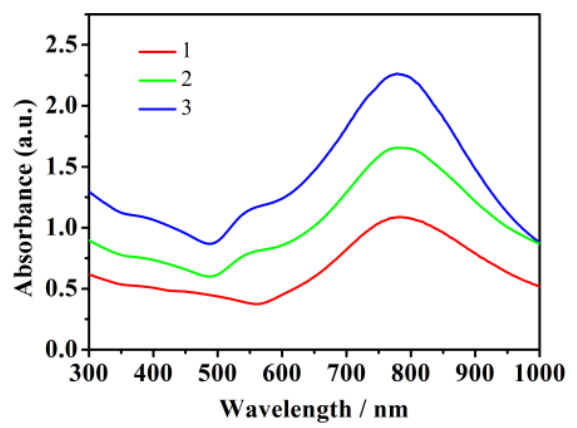

Figure S18. The UV-Vis spectra of 1-3 layers of the aptamer-modified gold nanofilm. 


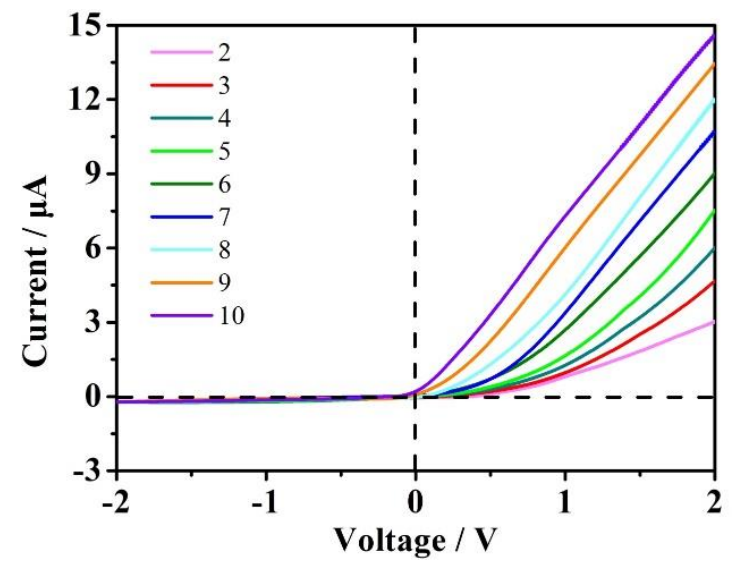

Figure S19. The I-U curves of Au-AAO ion channels composed by with different layers of gold nanofilms.
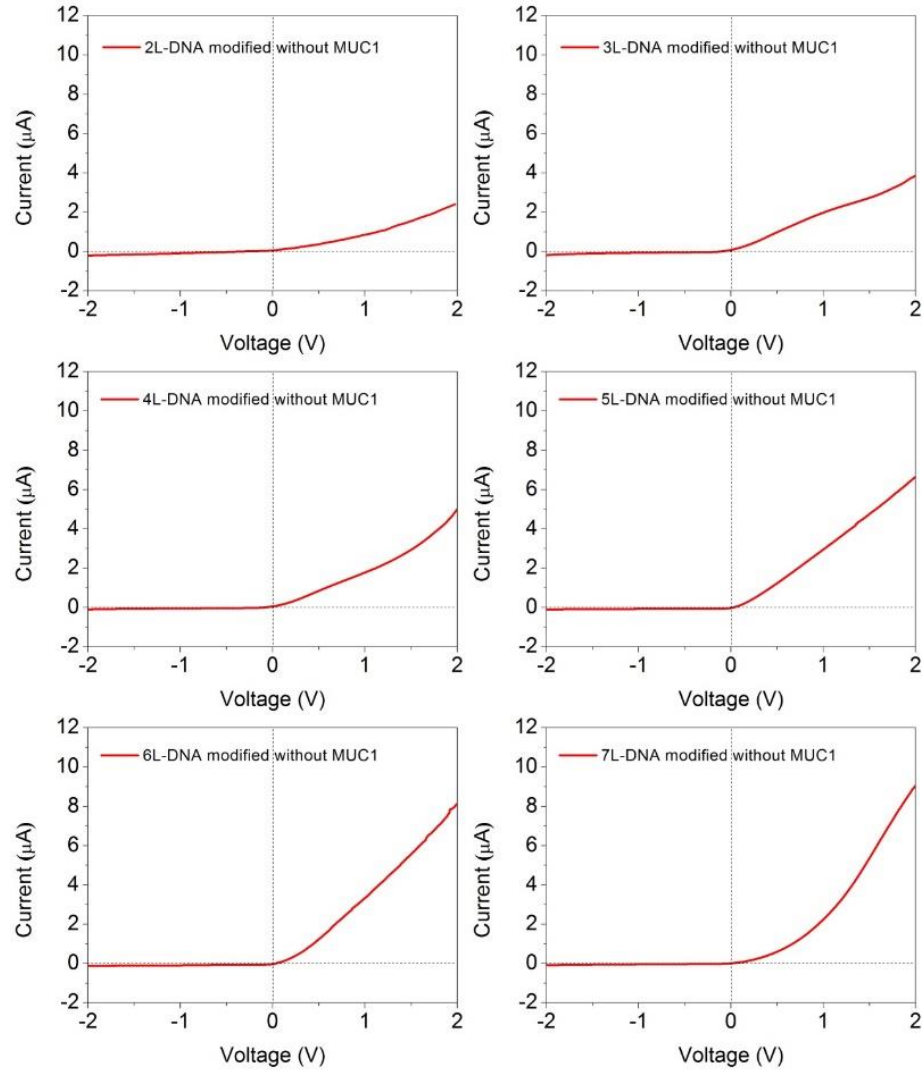

Figure S20. The I-U curves of the DM systems with different layers of gold nanofilms before adding the MUC1 target $(10 \mathrm{pg} / \mathrm{mL})$. 

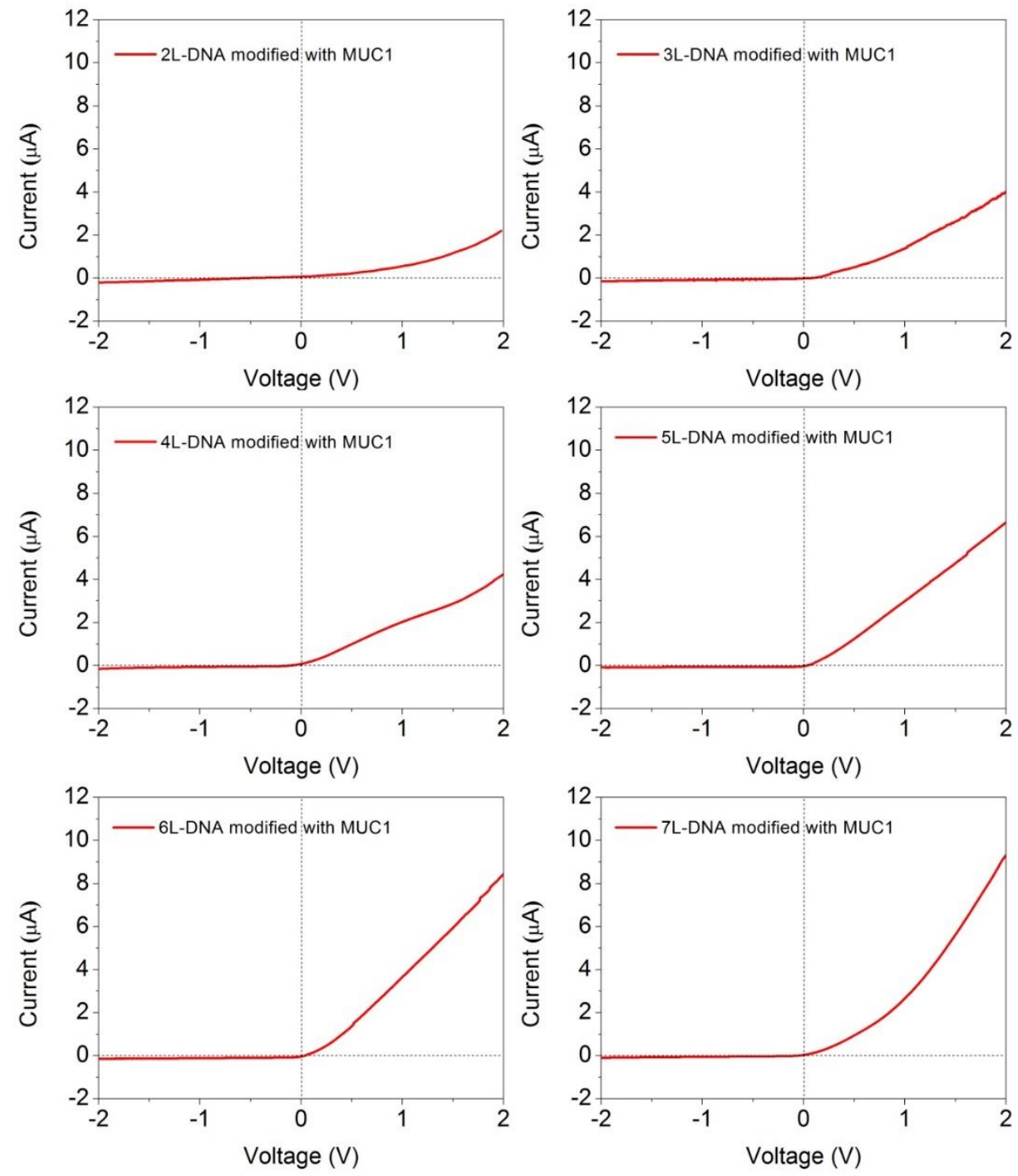

Figure S21. The I-U curves of the DM systems with different layers of gold nanofilms after adding the MUC1 target $(10 \mathrm{pg} / \mathrm{mL})$. 

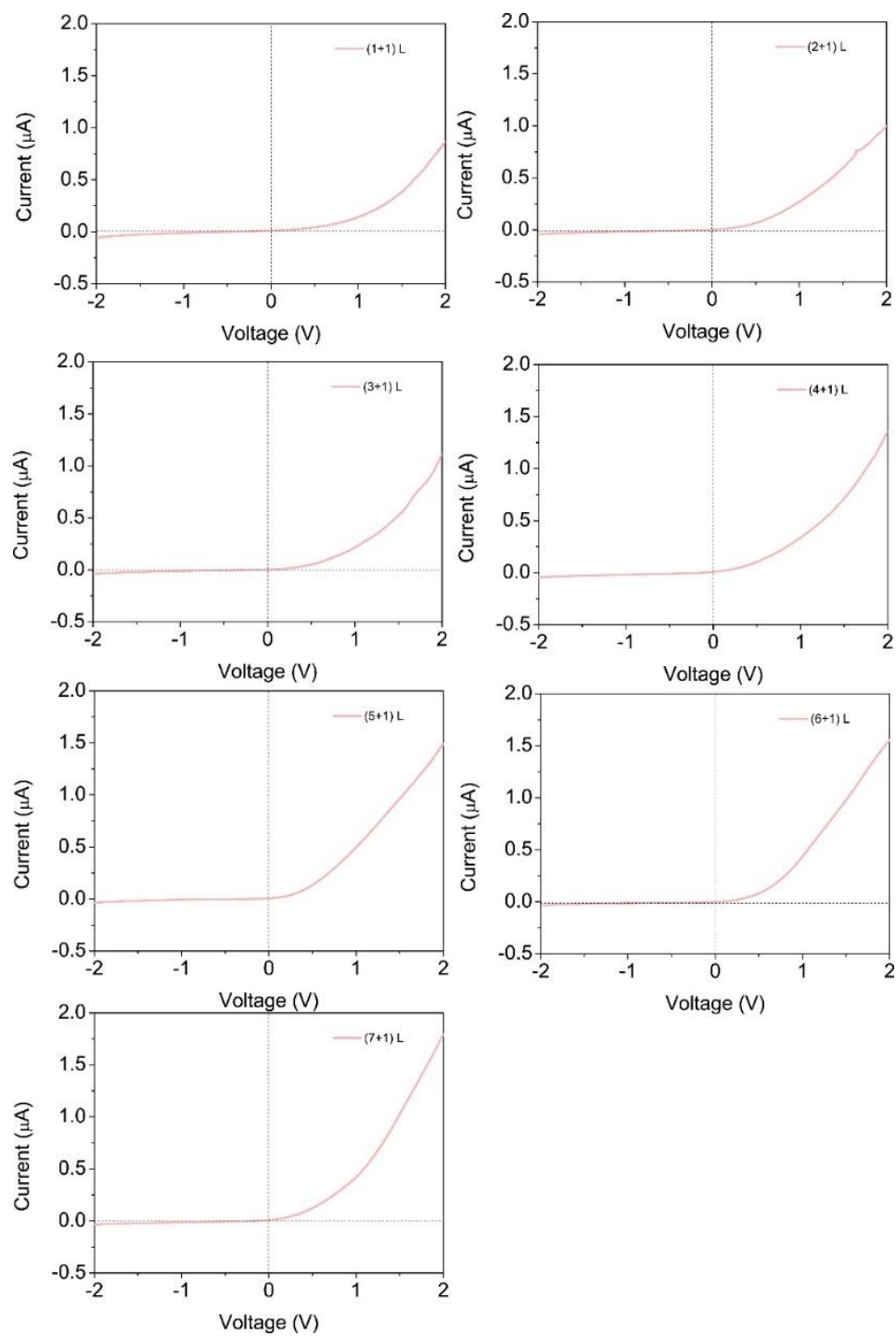

Figure S22. The I-U curve for different layers of nanofilms after the outer layer modification of aptamer. 

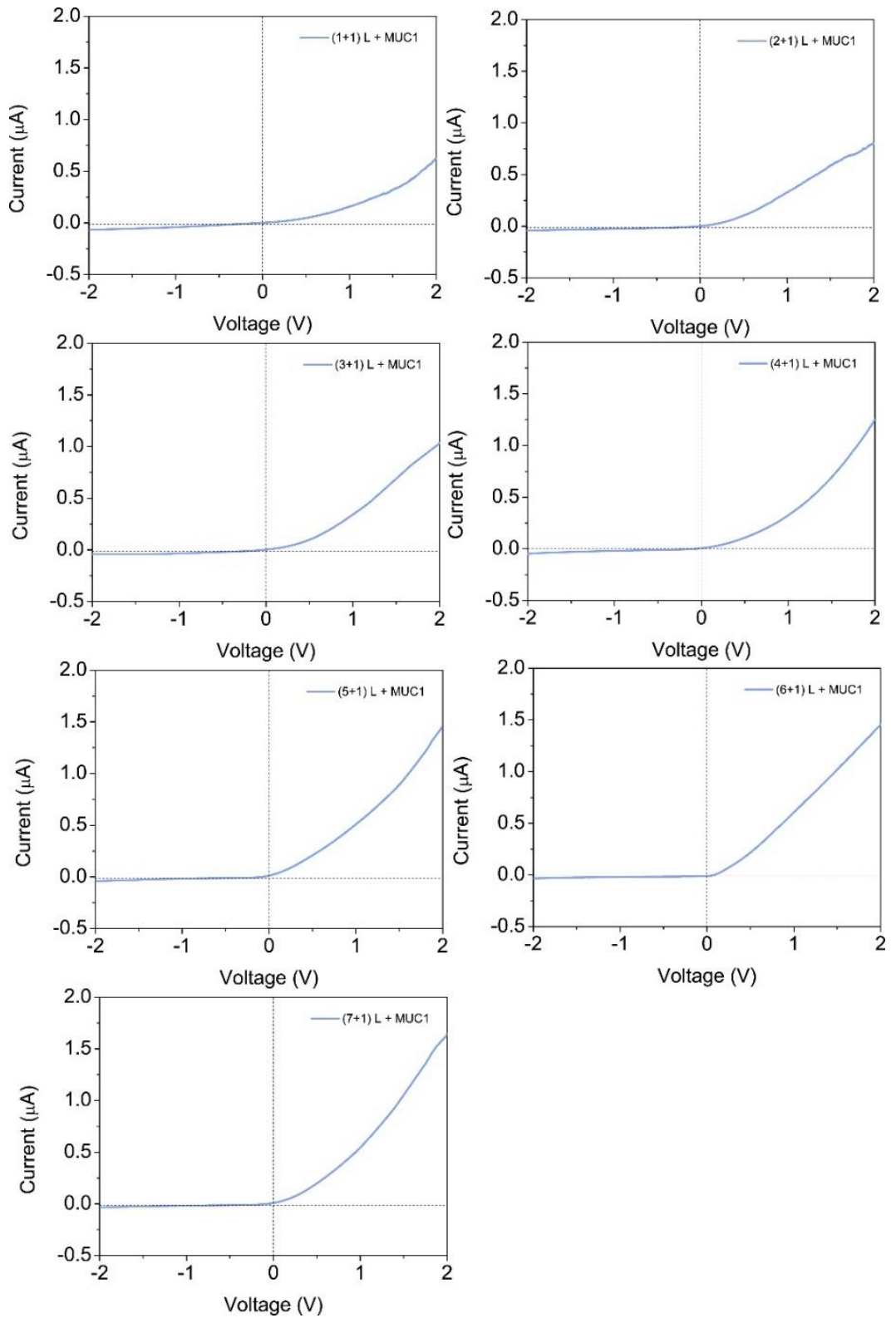

Figure S23. The I-U curve of $10 \mathrm{pg} / \mathrm{mL}$ MUC1 target was added to the nanofilms of different layers after the outer layer of the aptamer was modified. 


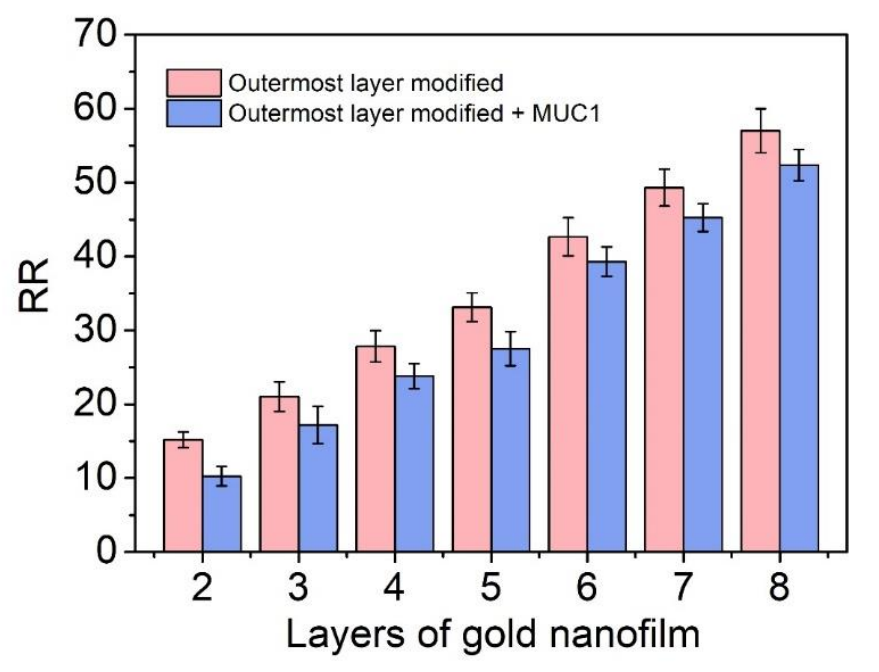

Figure S24. The RR statistics for different layers of nanofilms after modification of the outer layer of the aptamer, without or with adding the MUC1 target $(10 \mathrm{pg} / \mathrm{mL})$.

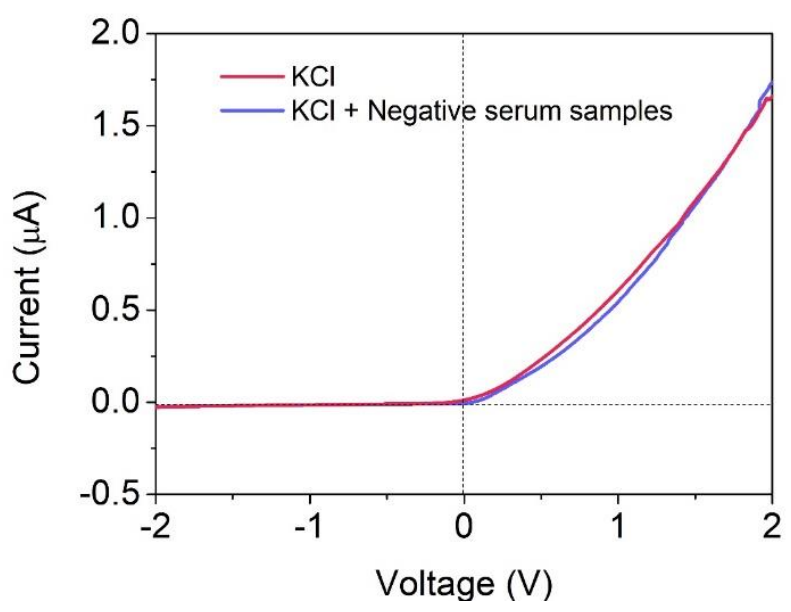

Figure S25. The I-U curve of the negative blood sample without MUC1 was added to the $\mathrm{KCl}$ electrolyte solution of the AU-AAO system, and the results showed that the real sample system would not affect the detection of MUC1. 


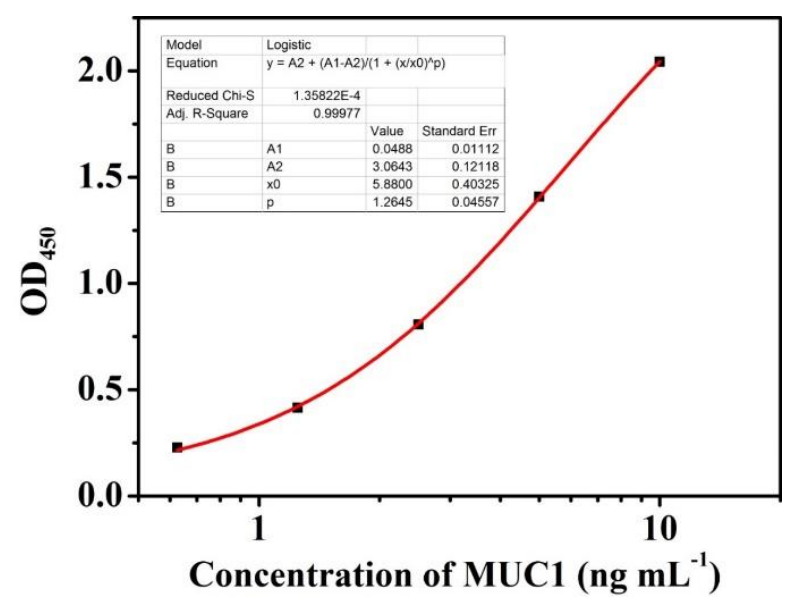

Figure S26. Standard curve of ELISA. 
Table S1. Comparison of different methods.

\begin{tabular}{|c|c|c|}
\hline No. & detection method & $\begin{array}{c}\mathrm{LOD} \\
\left(\mathrm{fg} \mathrm{mL}^{-1}\right)\end{array}$ \\
\hline 1 & Dual-Polar ECL ${ }^{3}$ & 5.8 \\
\hline 2 & Restriction of Intramolecular Motions (RIM)-ECL ${ }^{4}$ & 0.29 \\
\hline 3 & Doped metal-organic nanoplate ECL ${ }^{5}$ & 0.14 \\
\hline 4 & DNA Tweezer and Fluorescence ${ }^{6}$ & 2.6 \\
\hline 5 & SERS Immunoassay $^{7}$ & 10 \\
\hline 6 & Nanochannel-sensor (this work) & 0.0364 \\
\hline
\end{tabular}

Table S2. The research progress of nanochannel based biosensors.

\begin{tabular}{|c|c|c|c|c|}
\hline Analytes & $\begin{array}{c}\text { Nanochannel } \\
\text { types }\end{array}$ & $\begin{array}{c}\text { Functional } \\
\text { molecule }\end{array}$ & Linear range & $\begin{array}{c}\text { LOD } \\
\left(\text { fg mL }^{-1}\right)\end{array}$ \\
\hline $\begin{array}{c}\text { Alpha- } \\
\text { fetoprotein }^{8}\end{array}$ & $\begin{array}{l}\text { Polytetrafluoro } \\
\text { ethylene film }\end{array}$ & DNA & / & $1.0 \mathrm{fM}$ \\
\hline Thrombin $^{9}$ & AAO & DNA & l & $0.22 \mathrm{fM}$ \\
\hline Insulin ${ }^{10}$ & $\mathrm{AAO}$ & DNA & $10 \mathrm{pM}-10 \mathrm{nM}$ & $10 \mathrm{pM}$ \\
\hline Protein $^{11}$ & PET & Antibody & $\begin{array}{c}10 \mathrm{nM}-100 \\
\mathrm{nM}\end{array}$ & $10 \mathrm{nM}$ \\
\hline Streptavidin ${ }^{12}$ & PET & Biotin-PAH & I & $1 \mathrm{pM}$ \\
\hline MicroRNA $^{13}$ & $\mathrm{AAO}$ & DNA & $\begin{array}{c}0.1 \mathrm{fM}-0.1 \\
\mu \mathrm{M}\end{array}$ & $15.4 \mathrm{aM}$ \\
\hline MicroRNA $^{14}$ & $\mathrm{AAO}$ & DNA & $1.0 \mathrm{fM}-1.0 \mathrm{nM}$ & $1 \mathrm{fM}$ \\
\hline MicroRNA $^{15}$ & AAO & DNA & $10-1000 \mathrm{fM}$ & $4.53 \mathrm{fM}$ \\
\hline $\begin{array}{c}\text { Telomerase } \\
\text { activity }^{16}\end{array}$ & $\mathrm{AAO}$ & $\begin{array}{c}\text { Telomerase } \\
\text { substrate primers }\end{array}$ & $\begin{array}{l}\text { 10-5000 Hela } \\
\text { cells }\end{array}$ & Several cells \\
\hline $\begin{array}{l}\text { Circulating } \\
\text { tumor cells }{ }^{17}\end{array}$ & $\mathrm{AAO}$ & DNA & $\begin{array}{c}100-1000 \text { cells } \\
\mathrm{mL}^{-1}\end{array}$ & $\begin{array}{c}10 \text { cells } 100 \\
\mu \mathrm{L}^{-1}\end{array}$ \\
\hline
\end{tabular}

Table S3. Sequence of ssDNA used for catching MUC1.

\begin{tabular}{cc}
\hline Name & Sequence (5'to 3') \\
\hline MUC1 aptamer & TTT TTT TGC AGT TGA TCC TTT GGA TAC CCT GG \\
Irrelevant DNA & TTT TTT TGC AAT TGA TCG TTT GGA TAC CCT GG \\
\hline
\end{tabular}


Table S4. Comparison of real blood sample detection.

\begin{tabular}{|c|c|c|c|c|c|}
\hline $\begin{array}{l}\text { Serum } \\
\text { samples }\end{array}$ & 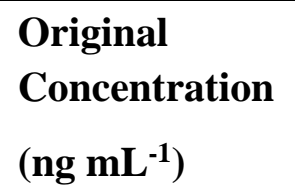 & 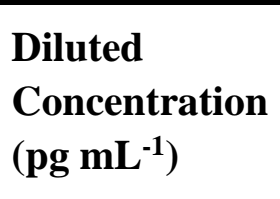 & $\begin{array}{l}\text { Detected } \\
\text { Concentration } \\
\left(\mathbf{p g} \mathbf{~ m L}^{-1}\right)\end{array}$ & $\begin{array}{l}\text { Recovery } \\
(\%)(n=3)\end{array}$ & SD \\
\hline 1 & 9.909 & 4.95 & $4.90 \pm 0.01$ & 98.56 & 0.0111 \\
\hline 2 & 8.239 & 4.12 & $4.08 \pm 0.05$ & 96.99 & 0.013 \\
\hline 3 & 8.663 & 4.33 & $4.32 \pm 0.03$ & 98.91 & 0.0115 \\
\hline
\end{tabular}

Table S5. Standard recovery test by different method.

\begin{tabular}{|c|c|c|c|c|}
\hline $\begin{array}{c}\text { Spiked } \\
\text { Concentration } \\
\left(\mathbf{p g ~ m L} \mathbf{~ m L}^{-1}\right)\end{array}$ & $\begin{array}{c}\text { ELISA } \\
\left(\mathbf{p g ~ m L} \mathbf{~}^{-1}\right)\end{array}$ & $\begin{array}{c}\text { Recovery }(\%) \\
(\mathbf{n}=\mathbf{3})\end{array}$ & $\begin{array}{l}\text { This Work } \\
\left(\text { pg mL } \mathbf{L}^{-1} \text { ) }\right.\end{array}$ & $\begin{array}{c}\text { Recovery }(\%) \\
(\mathbf{n}=3)\end{array}$ \\
\hline 1.00 & Not detected & 1 & $1.02 \pm 0.05$ & 99.37 \\
\hline 3.00 & Not detected & 1 & $2.99 \pm 0.01$ & 99.80 \\
\hline 5.00 & Not detected & 1 & $4.93 \pm 0.02$ & 99.54 \\
\hline
\end{tabular}




\section{Supplementary References}

(1) Ji, X.; Song, X.; Li, J.; Bai, Y.; Yang, W.; Peng, X., Size Control of Gold Nanocrystals in Citrate Reduction: The Third Role of Citrate. J Am Chem Soc 2007, 129 (45), 13939-13948.

(2) Zhao, X. L.; Xu, L. G.; Sun, M. Z.; Ma, W.; Wu, X. L.; Kuang, H.; Wang, L. B.; Xu, C. L., GoldQuantum Dot Core-Satellite Assemblies for Lighting Up MicroRNA In Vitro and In Vivo. Small 2016, 12 (34), 4662-4668.

(3) Zhou, Y.; Chai, Y.; Yuan, R., Highly Efficient Dual-Polar Electrochemiluminescence from Au-25 Nanoclusters: The Next Generation of Multibiomarker Detection in a Single Step. Analytical Chemistry 2019, 91 (22), 14618-14623.

(4) Yang, J.; Hu, X.; Kong, X.; Jia, P.; Ji, D.; Quan, D.; Wang, L.; Wen, Q.; Lu, D.; Wu, J.; Jiang, L.; Guo, W., Photo-induced ultrafast active ion transport through graphene oxide membranes. Nat. Commun. 2019, $10(1), 1171$.

(5) Yao, L.; Yang, F.; Liang, W.; Hu, G.; Yang, Y.; Huang, W.; Yuan, R.; Xiao, D., Ruthenium complex doped metal-organic nanoplate with high electrochemiluminescent intensity and stability for ultrasensitive assay of mucin 1. Sensor Actuat B-Chem 2019, 292, 105-110.

(6) Yang, W.; Shen, Y.; Zhang, D.; Li, C.; Yuan, R.; Xu, W., Programmed Dual-Functional DNA Tweezer for Simultaneous and Recognizable Fluorescence Detection of microRNA and Protein. Anal Chem 2019, 91 (12), 7782-7789.

(7) Kamil Reza, K.; Wang, J.; Vaidyanathan, R.; Dey, S.; Wang, Y.; Trau, M., ElectrohydrodynamicInduced SERS Immunoassay for Extensive Multiplexed Biomarker Sensing. Small 2017, 13 (9), 1602902.

(8) Zhang, Z.; Li, T.; Sheng, Y.; Liu, L.; Wu, H. C., Enhanced Sensitivity in Nanopore Sensing of Cancer Biomarkers in Human Blood via Click Chemistry. Small 2019, 15 (2), e1804078.

(9) Zhao, X.-P.; Zhou, Y.; Zhang, Q.-W.; Yang, D.-R.; Wang, C.; Xia, X.-H., Nanochannel-Ion Channel Hybrid Device for Ultrasensitive Monitoring of Biomolecular Recognition Events. Anal. Chem. 2019, $91(1), 1185-1193$.

(10) Li, X.; Zhang, T.; Gao, P.; Wei, B.; Jia, Y.; Cheng, Y.; Lou, X.; Xia, F., Integrated Solid-State Nanopore Electrochemistry Array for Sensitive, Specific, and Label-Free Biodetection. Langmuir 2018, 34 (49), 14787-14795.

(11) Siwy, Z.; Trofin, L.; Kohli, P.; Baker, L. A.; Trautmann, C.; Martin, C. R., Protein Biosensors Based on Biofunctionalized Conical Gold Nanotubes. J. Am. Chem. Soc. 2005, 127 (14), 5000-5001.

(12) Ali, M.; Yameen, B.; Neumann, R.; Ensinger, W.; Knoll, W.; Azzaroni, O., Biosensing and Supramolecular Bioconjugation in Single Conical Polymer Nanochannels. Facile Incorporation of Biorecognition Elements into Nanoconfined Geometries. J. Am. Chem. Soc. 2008, 130 (48), 1635116357.

(13) Zhao, X.-P.; Liu, F.-F.; Hu, W.-C.; Younis, M. R.; Wang, C.; Xia, X.-H., Biomimetic NanochannelIonchannel Hybrid for Ultrasensitive and Label-Free Detection of MicroRNA in Cells. Anal. Chem. 2019, $91(5), 3582-3589$.

(14) Huo, X.-L.; Yang, H.; Zhao, W.; Xu, J.-J.; Chen, H.-Y., Nanopore-Based Electrochemiluminescence for Detection of MicroRNAs via Duplex-Specific Nuclease-Assisted Target Recycling. ACS Appl. Mater. Inter. 2017, 9 (38), 33360-33367.

(15) Shi, L.; Mu, C.; Gao, T.; Chen, T.; Hei, S.; Yang, J.; Li, G., DNA nanoflower blooms in nanochannels: a new strategy for miRNA detection. Chem. Commun. 2018, 54 (81), 11391-11394.

(16) Liu, X.; Wei, M.; Liu, Y.; Lv, B.; Wei, W.; Zhang, Y.; Liu, S., Label-Free Detection of Telomerase 
Activity in Urine Using Telomerase-Responsive Porous Anodic Alumina Nanochannels. Anal. Chem. 2016, 88 (16), 8107-8114.

(17) Cao, J.; Zhao, X.-P.; Younis, M. R.; Li, Z.-Q.; Xia, X.-H.; Wang, C., Ultrasensitive Capture, Detection, and Release of Circulating Tumor Cells Using a Nanochannel-Ion Channel Hybrid Coupled with Electrochemical Detection Technique. Anal. Chem. 2017, 89 (20), 10957-10964. 